\title{
Research on MTI Theses of Inner Mongolia University-Taking the Theses of the Students of Grade 2011-2013 as a Case*
}

\author{
Huaiyu $\mathrm{Mu}$ \\ Inner Mongolia University, China
}

\begin{abstract}
This paper has conducted a quantitative investigation and analysis of the selection of research topics and writing models of the MTI theses of the students of Grade 2011 to Grade 2013 at Inner Mongolia University, and had a deep probe into the actual application and acceptance of the current modes of MTI theses. Based on the findings, the author suggests that in procession of writing MTI theses, the students should be required to first select a highly professional translation project which has not been translated before, and then write a research report on the practice of translation. The writing of MTI theses should embody its distinctive characteristics and avoid the convergence with the forms of such academic-oriented theses as those on translation studies, thoroughly removing the "academic" tendency and keeping its "professional" feature, but at the same time, the academic norms that MIT theses should have can't be reduced.
\end{abstract}

Index Terms - Inner Mongolia University, MTI, Thesis, Selection of Research Topics

\section{INTRODUCTION}

In 2011, the program of Master of Translation and Interpreting (MTI) was set up at Inner Mongolia University, and since then MTI enrollment and cultivation of talents in translation and interpreting have become one of the core contents of the postgraduate education at Inner Mongolia University. The total number of students coming to register for MTI at Inner Mongolia University has been increasing yearly, and by July 2015, 293 students had been enrolled in all and 174 students had graduated. However, with the enrollment number of MTI at Inner Mongolia University increasing, the problems about the selection of research topics and writing models of the students' MTI theses have become more and more pronounced. Therefore, the author has conducted a quantitative investigation and an analysis of the selection of research topics and writing models of the MTI theses of the students from Grade 2011 to Grade 2013 at Inner Mongolia University, investigated the problems arising in the current MTI theses and further discussed the solutions to them.

\section{Statistics AND ANALYSIS}

The author went through 174 MTI theses of the students from Grade 2011 to Grade 2013 at Inner Mongolia University, and the forms of the students' theses are respectively research papers, translation practice reports and translation experiment reports. Among these theses, there are 72 research papers, accounting for $41.4 \%$ of the total number of the theses; 99 translation practice reports, accounting for $56.9 \%$; 3 translation experiment reports, accounting for $1.7 \%$. From these findings we can see that the MTI theses of Inner Mongolia University are in the transition from the model of traditional academic-oriented theses to the model of practical-oriented theses, gradually reflecting the distinctive characteristics of MTI education focusing on the practice. However, the number of translation experiment report embodying distinctive practical features, one of the three forms of theses offered in Guiding Syllabus for MTI Education, only accounts for $1.7 \%$, so far less than the number of the first two forms of theses that we should pay attention to this phenomenon.

Table 1 reflects the classification statistics on the number in the three forms of translation experiment report, research paper and translation practice report in the MTI theses of the students from Grade 2011 to Grade 2013 at Inner Mongolia University. There are some differences in the three forms of the students' theses.

\footnotetext{
* This paper is the research result of both "Research and Practice on the Standard of MTI Theses in the Inner Mongolia Autonomous Region" (YIG20151012614) of Scientific Research Project of the Department of Education of the Inner Mongolia Autonomous Region and "Scientific Research Project on Foreign Language Teaching of National Universities" ( 2016NM0007B).
} 
TABLE 1.

CLASSIFICATION STATISTICS OF THE MTI THESES OF THE STUDENTS FROM GRADE 2011 TO GRADE 2013 AT INNER MONGOLIA UNIVERSITY

\begin{tabular}{|l|l|l|l|l|}
\hline Grade & Major & Translation experiment report & Research paper & Translation practice report \\
\hline \multirow{2}{*}{ Grade 2011 } & Translation & 0 & 7 & 24 \\
\cline { 2 - 6 } & Interpreting & 0 & 6 & 17 \\
\hline Grade 2012 & Translation & 0 & 4 & 24 \\
\cline { 2 - 6 } & Interpreting & 0 & 29 & 1 \\
\hline \multirow{2}{*}{ Grade 2013 } & Translation & 0 & 0 & 32 \\
\cline { 2 - 6 } & Interpreting & 3 & 26 & 99 \\
\hline Total & 3 & 72 & 1 \\
\hline
\end{tabular}

Next, the author makes a deep and detailed analysis of the inclination reflected in the selection of the three forms of the MTI theses.

\section{A. Translation Practice Report}

The main problems existing in the 99 translation practice reports are as follows. In the first place, some students did not classify, explain and analyze the difficult problems and puzzles that they met with in the process of translation, and even didn't explain how to apply relevant translation theories and appropriate translation methods and techniques to solve these difficulties in their translation practice reports, and of course they could not translate the projects accurately. What's more, they didn't rethink the whole translation process, the translation strategies and the application of relevant theories, they also did not give classified elaboration and analysis, summary and conclusion of the experience and law of translation, and thus they even didn't refer to what inspirations they got in the process of translation and what innovations they made in translation theories and methods. They just described the translation process and translation examples in a dull, flat style. The number of such kind of translation practice reports is 44 , accounting for $44 \%$.

In comparison, more than half of the students can give a detailed analysis, summary and conclusion on the difficult problems and puzzles that they met with in the process of translation and can apply the scientific methodology and a certain translation theory that they have mastered to further analyzing and explaining these problems and then give the corresponding solutions. The number of such kind of translation practice reports is 55, accounting for $55.6 \%$.

The type of materials for translation practice report reflects the inclination of the material selection of the students.

TABLE 2:

TYPE OF MATERIALS FOR TRANSLATION PRACTICE REPORT

\begin{tabular}{|l|l|l|l|}
\hline \multicolumn{2}{|l|}{ Type of materials for translation practice reports } & Number of theses & Percentage \\
\hline \multirow{2}{*}{ Translation report } & Literary text & 62 & $62.6 \%$ \\
\cline { 2 - 4 } & Non-literary text & 35 & $35.4 \%$ \\
\hline Interpreting report & 2 & $2.0 \%$ \\
\hline Total & 99 & $100.0 \%$ \\
\hline
\end{tabular}

Among the translation texts as the written translation projects chosen by the students, the number of literary texts is far more than that of the non-literary texts. According to the author's investigation, the main reason for the case is that, compared to other types of texts, the studying and appreciation of literary works run through the whole process of the education of the students, who are more familiar with their linguistic features, and thus in the process of translation, the difficulty is relatively smaller, therefore, it is easier to control. But in that case, MTI students' comprehensive translation practice ability can not be reflected in their theses, and it is also contrary to the original intention that MTI aims to cultivate applied, practical and professional talents. In addition, " $90 \%$ of total volume of translation in the world is the translation of technology and business, while literary translation accounts for only about $1 \%$ of the total volume of translation" (Sun, 2015, p.106), and in China, "In terms of the current situation of the translation of the book market, literary translation only has a proportion of $8 \%$ among the published translated books, the rest are non-literary translation" (Xu, 2010, p.52), and "At present there is a huge gap in the number of first-rate, professional and applied translating and interpreting talents in China" (Guo, 2012). Therefore, the author thinks the tutors should give correct guidance to their students when they select their translation projects.

In the literary texts, most are novels with the number of 37. Other types, such as culture, children's literature, history and biography, are more evenly distributed; in the non-literary texts, the selection of materials is mostly related to science and technology and academic, with the number of 8 and 9 respectively; the number of other types of texts such as political essays, tourism, linguistics, foreign publicity, current politics, film and television and so on are $1-5$. However, in all the 99 translation-practice-report-based MTI theses, only 2 theses selected interpreting projects, but they didn't give classified exploration and analysis to the difficulties they met with in the practical process of interpreting protects, and perfect the translation methods, summarize the experience and law of translation and so on.

In the 19 oral interpreting-oriented translation practice reports, only 2 theses selected interpreting projects, the remaining 17 theses all selected translation projects. Up to now, whether the distinction between interpreting-oriented theses and translation-oriented theses should be made has not been regulated in the existing forms of theses. According to the author's investigation findings, the main reason for the above phenomenon is that, compared with the economically developed provinces and cities, there is a lack of geographical advantage in the Inner Mongolia Autonomous Region, the students' opportunities of interpreting practice are very limited, the difficulty in the collection 
of interpreting projects is far greater than that of the translation projects for them. In this case, for the sake of safety, many interpreting-oriented students have to select other forms of theses which are relatively easy for them because there are no relevant interpreting practice. Therefore, it is necessary for us to make a positive exploration in whether the distinction between interpreting-oriented theses and translation-oriented theses should be made in the thesis form of the translation practice report, and adopt what kind of way and how to distinguish them, how to embody the characteristics of the interpreting-oriented thesis form.

According to the author' investigation, the main reason why the translation practice reports of the students did not embody the applied, practical and professional features of MTI education is that the students did not have enough opportunities for translation practice so that they could not learn the changing needs of the translation industry market in time and experience the real translation work, and in that case they could not make a rich abundant accumulation of the selection of topics for their translation practice reports. As a professional degree education, MTI education's career direction is very clear, that is to cultivate applied, practical and professional translators and interpreters, which requires that translation teaching must be consistent with social needs, the professionalization requirements of the translation industry and the content of the actual translation work. Kong and Wang (2011) argue that it is a common practice to cultivate the professional translation talents in the world by combining the teaching of MTI with the students' translation practice in the professionalized way so each university offering the MTI programs should be good at creating and exploring opportunities for translation practice and give the practice-oriented and profession-oriented training to the students, and fully cooperate with the government, enterprises and institutions, foreign-funded and export-oriented enterprises, translation companies, overseas-study agencies, and, at the same time, carry out extensive international cooperation to ensure that the students have as many opportunities as possible in the translation practice to get a systematic and real profession training. This kind of opportunities will provide the students an important platform to obtain the experience of translation practice, and in this way the students could take an active part in the real translation projects, have a good knowledge of various network resources, translation software, translation techniques, and related equipment and learn to grasp and use them effectively, experience the real translation work and learn about the practical needs of the translation industry, find out their weaknesses, broaden their horizons, through which the students could achieve sufficient amount of practice and translation, making their translation competence further improved. Through this kind of practical activities the students could make a rich accumulation of the selection of the topics for the translation practice reports, which, at the same time, could also shorten their adaptation period of being engaged in translation work after graduation and make them become qualified translators and interpreter as soon as possible.

\section{B. Experimental Report}

Guiding Syllabus for MTI Education puts forward three basic forms of thesis, among which, the stipulation on "experimental report" is that students carry out experiments on a certain section of interpreting or translation under the tutor's guidance, and then analyze the experimental results, and write an experimental report with at least 10000 words. The experimental design should be described accurately in the experimental report. And a complete experimental design theoretically should include "research objects, research goals and research expectations based on the cognitive interest and need; media / tools, description of the experimental process, operation procedure; research hypothesis; experimental text; the methods and problems bringing about data; questionnaire (focusing on text analysis); subjects' qualification and selected conditions, and controllable/uncontrollable factors/variables; the methods for data analysis related to research goals" (Miao \& Liu, 2010, p.95).

The author analyzed the only three experimental reports in the MTI theses based on the above standard. One of the three experimental reports was basically completed on the basis of the standard of experimental design, the other two just got the relevant data by experimental means, and then described and analyzed the data, and they need to be further regulated.

There are only 3 theses in the form of experimental reports in the 174 MTI theses. This result requires us to have a serious rethink. Li and Pan (2012) think that, as one of the core semantics of the experimental report, the "experiment" is an empirical research, an elaborate design, and it is a method of studying the causal relationship between variables by manipulating certain factors under highly controlled conditions. When introducing the experiment method for translation research, Williams and Chesterman (2002) make a distinction between it and naturalistic (or observational) studies empirical research: An experimental study, on the other hand, deliberately interferes with the natural order of things in order to isolate a particular feature for study and, as far as possible, to eliminate other features that are not relevant to the research. You set up controlled conditions under which you test something. You can then compare the results with those produced under some conditions, or those that occurred in a natural situation. For instance, you might want to compare the ways in which trainee translators revise their own texts with the ways professionals do. You therefore arrange two groups that do not differ (you hope) in any other significant way except trainee-vs.-professional, give them the same translation task, and the same deadline, and see what happens. That is to say, researchers need to intervene in the process of the object's occurrence or development in order to isolate or highlight the specific characteristics of the study, so as to drown a conclusion by comparing with the results of the control group. The main reason why there are only 3 theses in the form of experimental reports in the 174 MTI theses, according to the author's survey, the main reason is that, the experimental process is very difficult to operate, what's more, it involves many factors such as hypothesis, sampling construction group, variable control and so on. This kind of topics is a big 
challenge for academic-oriented graduate students, not to mention applied graduate students with less academic training (Huang, 2012). Thus, it seems that experimental report, as one of the given forms of the MTI theses, is somewhat unrealistic and unreasonable for the students.

\section{Research Paper}

The form of research paper accounts for $41.4 \%$ in the selection of topics of the MTI theses. Among them, the number of research papers in the graduation theses of students of Grade 2012 and Grade 2013 majoring in interpreting accounts for $96.6 \%$ and $86.7 \%$ respectively, which greatly deviates from the training goal of MTI education focusing on practice and application. According to Guiding Syllabus for MTI Education, the goal of MTI is to "cultivate high-level, applied and professional interpreters and translators with all-round development of morality, intelligence and physical fitness, adapting to the needs of global economic integration and enhancing the international competitiveness of the country, and to the needs of national economic, cultural and social construction". In accordance with this requirement, what MTI cultivates is a translation team with a high level of professional competence, and the students will eventually connect the translation knowledge and related theories that they have learned at school with social needs. What's more, profession-oriented degree education "is different from the one of the general research-oriented degree which focuses on theoretical and academic research. Profession-oriented degree education aims to cultivate high-level and applied professionals with certain profession's backgrounds" (Zhong, 2007, p.5). Therefore, the writing of MTI theses should also embody its distinctive characteristics, avoiding the convergence with the forms of such academic-oriented theses as those on translation studies.

In a survey of 72 academic-oriented "research papers", the main problem is that, some students did not combine with a specific translation project or a specific problem in the process of discussion. They only discussed the translation skills, translation strategies or translation theories relatively separately, and the topics were too broad. The number of such theses was 16 , accounting for $22.2 \%$. "It is especially important for the research topic to put forward the research issue correctly, because any scientific research starts from an issue raised, and without the issue, there will be no development of scientific research" (Luo\& Mu, 2010, p.98). While most students can analyze specific translation projects or specific problems in their theses, the number of such theses is 56, accounting for $77.8 \%$. According to the different fields, these theses are divided into "translation research" and "interpreting research", and among these topics the majority are "interpreting research", with the number of 48 , accounting for $85.7 \%$.

"Master of Translation and Interpreting is a new idea and a new model for our country's cultivation of specialized personnel in translation after referring to the successful experience of cultivating translators for many years in European and American countries and Hong Kong and Taiwan areas" (He \& Mu, 2007, p.12). As a professional degree education, MTI education's career direction is very clear, that is to cultivate applied, practical and professional translators and interpreters. What's more, "the cultivation of translation ability is the life of MTI, and practice is the only way to cultivate the ability of translation" (Li, 2013, p.52), and this kind of teaching idea should also be fully reflected in the theses of MTI, with translation ability as the most important evaluation objective, fully embodying its features focusing on practice and application. But at the same time, the academic norms that the theses should have cannot be reduced or ignored, because "that we give special attention to the characteristics of practice does not mean giving up the cultivation of academic ability, nor does it mean that MTI graduation theses can completely disregard the general rules of the writing of academic theses and be finished in a slapdash way" (Wu, 2010, p.14). And more importantly, the teaching of translation theory can not be ignored in the course of the cultivation of MTI education, "paying attention to avoiding the teaching idea of simple pragmatism due to the lack of guidance of scientific theory, and avoiding a tendency covering up another tendency" (Dong, 2012, p.27).

TABLE 3:

CLASSIFICATION STATISTICS FOR THE RESEARCH PAPERS COMBINING A SPECIFIC TRANSLATION PROJECT OR A SPECIFIC PROBLEM

\begin{tabular}{|l|l|l|}
\hline Combining a specific translation project or a specific problem & Number of theses & Percentage \\
\hline Translation research & 8 & $14.3 \%$ \\
\hline Interpreting research & 48 & $85.7 \%$ \\
\hline Total & 56 & $100.0 \%$ \\
\hline
\end{tabular}

\section{CONCLUSIONS}

Through the statistics and analysis of the above survey data, the author finds that there are some problems in the topic selection of the MTI theses of the students of Grade 2011 to Grade 2013 at Inner Mongolia University. In the first place, the selection of topics of the research papers still occupies a large proportion, and the proportion of literary texts in the translation practice reports is too large. In the second place, in the translation practice reports, nearly half of the selection of the topics just described the process of translation, and they neither gave detailed exposition, exploration, generalization and summary of the specific difficulties and their reasons encountered in the translation process and the corresponding solutions to them, nor explained and rethought the process of translation, and summarize the law of translation and the experience of translation with relevant translation theories and methodology. Finally, in the research papers, due to the lack of corresponding academic theoretical background and training, a considerable number of 
students' theses only gave abstract exposition from a macro perspective, and the selection of research topics are more broad and lack of pertinence.

Based on the above problems, the author suggests that, first of all, students should be encouraged to step out of the classroom to take an active part in social practice, understand the actual needs of the translation industry market, applying their language knowledge and translation theories learned in the classroom to translation practice, closely connecting with social needs, increasing practical experience and laying a solid foundation for becoming an excellent professional interpreter and translator after graduation. The students should also keep it in mind that never mistakenly believe that "foreign language learning is translation learning, and a professional specializing in a foreign language is the one in translation" (Zhong, 2008, p.5). Second, "the core task of translation teaching is to cultivate the students' competence to translate" (Mu, 2006, p.46),thus, in the process of writing MTI theses, the students should be required to select highly professional translation projects which have not been translated before or the ones that they undertook, embodying the necessary ability possessed by high-level, applied and professional interpreters and translators cultivated by MTI education, and then write research reports on the translation practice, making the students' comprehensive translation practice ability truly embody in their theses. But at the same time, the teaching of translation theory must not be ignored. "Translation theory is the substantive reflection of the law of translation" (Hao \& Zhang, 2015, p.15). So the students should be required to have certain theoretical accomplishment. Accurate and appropriate translation comes from the strong support of translation theory, and the lack of relevant theoretical knowledge will greatly affect the improvement of translation practice ability. As Ulrych put forward that there are historical and theoretical factors in the specialized skills of all the professional members (Ulrych, 2005). Therefore, only through the organic combination of translation theory and translation practice can students' comprehensive and skilled practical ability of translation be effectively improved, making them leisurely deal with translation tasks in different fields in their future jobs. Thus, the writing of MTI theses should also embody its distinctive characteristics, avoiding the convergence with the forms of such academic-oriented theses as those on translation studies, thoroughly removing the "academic" tendency and keeping its "professional" feature.

\section{REFERENCES}

[1] Dong, H. X. (2012). MTI Education: Problems and Solutions. Research in Teaching, 3, 26-28.

[2] Guo, X.Y. (2012). An Analysis Report on the Strategic Planning of Investment for Forecast of the Development Prospect of China's Language Service Industry. http://www.qianzhan.com/report/detail/.5032f3a0834b466b.Html (accessed 10/03/2015).

[3] Hao, X. \& Zhang, J. Z. (2015). On Term Applied Ability for Scientific Translators. China Terminology, 6, 14-17.

[4] He, Q. Z. \& Mu, L. (2007). Translation and Foreign Language Teaching. Chinese Translators Journal, 4, 11-12.

[5] Huang, G. W. (2012). A Guide to Writing MTI Dissertations. Beijing: Foreign Language and Research Press.

[6] Kong, L.C. \& Wang, H. (2011). Cool Reflections in the Heat Wave of MTI. Foreign Language World, 3, 9-15.

[7] Li, C.Y. (2013). Research on education duration for MTI education. Shanghai Journal of Translators, 2, 51-53.

[8] Li, Z.\& Pan, L. X. (eds.) (2012). Introduction to the Methods of Social Science Research. Chongqing: Publishing House of Chongqing University.

[9] Luo, L.\& Mu, L. (2010). Selection of Research Topics: an Important Part of Research Methods of Translation Studies. Foreign Languages in China, 6, 98-106.

[10] Miao, J.\& Liu, Y. C. (2010). An Empirical Study of Translation---Theory, Method and Development. Foreign Languages in China, B, 92-97.

[11] $\mathrm{Mu}, \mathrm{L}$. (2006). Translation competence and translation testing. Shanghai Journal of Translators, 2, 43-47.

[12] Sun, H. (2015). Research on the Professional Development of MTI from the Perspective of Localization. Journal of Henan Radio \& TV University, 2, 104-107.

[13] Ulrych, M. (1996). Real-world Criteria in Translation Pedagogy. In Dollerup \& Appel (Eds.), Teaching Translation and Interpreting 3: New Horizon. Amsterdam/Philadelphia: John Benjamins, 251-259.

[14] Williams, J. \& Andrew C. (2002). The Map: A Beginner's Guide to Doing Research in Translation Studies. Manchester: St. Jerome Publishing House.

[15] Wu, G. (2010). Formulation of the Writing Scheme for MTI Theses and Some Problems Appearing at Present. East Journal of Translation, 2, 14-16.

[16] Xu, J. (2010). Reflections on MTI. Chinese Translators Journal, 1, 52-54.

[17] Zhong, W. H. (2008). Modeling the Training of Professional Translators and Interpreters: Exploration and Practice. Foreign Languages in China, 6, 4-8, 14.

[18] Zhong, W. H. (2007). Master of Translation and Interpreting (MTI) and Its Challenge to Foreign language Teaching in China. Foreign Languages in China, 4, 4-7, 12.

Huaiyu Mu was born in Hohhot, the Inner Mongolia Autonomous Region, China in 1978. He received his MA degree in foreign linguistics and applied linguistics from Inner Mongolia University, China in 2002.

$\mathrm{He}$ is currently a lecturer in the Foreign Languages College, Inner Mongolia University, Hohhot, China. His research interests include translation studies and American literature. 